\title{
Relationship of Various Prognostic Factors with Outcome of Treatment of Chronic Duodenal Ulcer Perforation Patients
}

Sakhawat Mahmud Khan ${ }^{1 *}$

Meer Mahbubul Alam²

Shahin Akhter ${ }^{3}$

Didarul Alam ${ }^{4}$

'Department of Urology

Chittagong Medical College

Chittagong, Bangladesh.

${ }^{2}$ Department of Surgery (Retired)

M.A.G. Osmani Medical College

Sylhet, Bangladesh

${ }^{3}$ Department of Physiology

Cox's Bazar Medical College

Cox's Bazar, Bangladesh.

${ }^{4}$ Department of Paediatrics

University of Science \& Technology, Chittagong (USTC)

Chittagong, Bangladesh.
*Correspondence to:

\section{Dr. Sakhawat Mahmud Khan}

Assistant Professor

Department of Urology

Chittagong Medical College

Chittagong, Bangladesh.

Mobile : +8801814902579

Email : K.sakhawat@ymail.com.

\begin{abstract}
Background: In acute abdominal conditions, chronic duodenal ulcer perforation is a very common surgical emergency that overwhelm the surgical ward throughout the year. Especially in the tropics and more in our country, peptic ulcer disease causes a major health problem. Objectives: To assess the usefulness of the prognostic factors in terms of morbidity and mortality in the treatment of perforated duodenal ulcer patient. Methods: This was a prospective study during the period from January 2003 to December 2003 in M.A.G. Osmani Medical College Hospital, Sylhet. The study included 100 cases of perforated chronic duodenal ulcer. Patients were randomly collected from all surgical units of SOMCH, Sylhet. Operation was done by simple closure with omental graft in all cases. Data analyzed by appropriate statistical method (Mean, SD \& $\lambda^{2}$ test). Results: Highly significant relationship was found between increased age ( $>50$ years) of patients with perforated duodenal ulcer and mortality $(\mathrm{p}<0.001)$. Lethality rate was higher in patients operated after 24 hours of onset of symptom in relation to patients operated within 24 hours of onset of symptom, $(\mathrm{p}<0.05)$. Different postoperative complications were prevalent in patients operated after 24 hours of onset of symptom, on the other hand complication rate was low in patients operated within 24 hours $(\mathrm{p}<0.001)$. There was also longer hospital stay in lately operated patients (more above median) than patients operated within 24 hrs $(p<0.001)$. Mortality was higher in cases of purulent peritoneal fluid, where as it was nil in case of billous and serosanguinous fluid $(p<0.001)$. More complications were developed in patients with purulent peritoneal fluid in comparison to billous and serosanguinous nature $(\mathrm{p}<0.001)$. There was more mortality in patients with preoperative shock in comparison with no features of shock $(p<0.001)$. More complications were noted in patients with preoperative shock than in patients with no features of shock $(\mathrm{p}<0.01)$. Conclusion: Delayed operation, preoperative shock, more age and gross peritoneal sepsis bear a direct relationship with outcome of treatment chronic duodenal ulcer perforation patients.
\end{abstract}

Key words : CDU; perforation; abdominal dyspepsia.

\section{INTRODUCTION}

Duodenal ulcer is the commonest cause of upper abdominal dyspepsia throughout the world and it is also common in our country ${ }^{1,2,3}$. During the last 20 years its incidence has decreased to less than halves in USA but has increased in developing countries ${ }^{4}$. Medical management of peptic ulcer disease has been revolutionized with the discovery of $\mathrm{H}_{2}$ blocker and proton pump inhibitor. The complications are likely to remain as before as $\mathrm{H}_{2}$ blocker has no effect on natural history of peptic ulcer ${ }^{5}$. It was found that amongst the patient with duodenal ulcer, complications were found in $62 \%$ of cases with pyloric stenosis in $37.3 \%$ cases, perforation in $24.5 \%$ cases and haematemesis in $0.3 \%$ cases $^{6}$. Perforation is the most common cause of death that occurs in about $10-15 \%$ of all recognized chronic duodenal ulcer patient ${ }^{7}$. Certain important factors are responsible in the pathogenesis of peptic ulcer perforation. They are fasting state, anxiety and stress, drugs, blood group etc ${ }^{8}$. 
Severity of illness and death are directly related to the interval between perforation and operation'. NSAIDs appear to be responsible for most of these perforations ${ }^{10}$. Preoperative shock, concurrent medical illness and long standing perforations were found to be independent risk variables related to post operative death $^{11}$. Although many risk factors have been identified, a reliable prognostic factor for perforated duodenal ulcer is still lacking. It seems that increased age, late presentation, gross peritoneal sepsis, perforation following drugs, perforation after meal, improper suture material used during repair increasing the mortality and morbidity following operation in our institute. So, the purpose of the study is to find out the various prognostic factors related to perforated duodenal ulcer.

\section{MATERIALS \& METHODS}

This was a prospective study during the period from January 2003 to December 2003 in M.A.G. Osmani Medical College Hospital, Sylhet. The study included 100 cases of perforated chronic duodenal ulcer. Patients were randomly collected from all surgical units of $\mathrm{SOMCH}$, Sylhet. The criteria of case selection were thorough history, clinical examination \& radiological findings with diagnosis of perforation of chronic duodenal ulcer and under gone operative treatment. Patient who refused operation or unfit for operation were treated by conservative methods excluded from the study. All the findings included in the protocol devised for the study. Operation was done by simple closure with omental graft in all cases.

In this study, age of the patients ranges from 17 to 80 years. The maximum distribution belongs to $4^{\text {th }}$ and then $3^{\text {rd }}$ decade of life. All the cases presented with more or less sudden severe agonizing pain in the upper abdomen. Plain X-ray abdomen in erect posture including the both domes of the diaphragm, were taken in all cases. Pneumoperitoneum was present in all cases except 3 cases (3\%), where the cases were diagnosed preoperatively and operated with the initial diagnosis of subphrenic abscess. A variable period elapsed between the time of admission into the hospital and laparotomy. In most cases this period was needed for resuscitation and preoperative preparation. $48 \%$ patients were operated after $24 \mathrm{~h}$. of onset of symptom and $52 \%$ cases were operated within 24 hours onset of symptom. Laparotomy performed in all cases, under general anaesthesia with upper midline incision. After opening abdomen peritoneal fluid was collected by sterile syringe and sent for culture and sensitivity. Simple repair with $2 / 0$ vicryl and interposition of omental patch done after sucking of peritoneal fluid.

Peritoneal fluid was billous in nature in 53\% cases, followed by purulent in $36 \%$ cases and serosanguinous in $11 \%$ cases.

There were positive growth on culture and sensitivity of peritoneal fluid present in $28 \%$ cases and no growth were detected in $72 \%$ cases. E. Coli detected in $57.14 \%$ cases followed by proteus in $28.57 \%$ cases and others in $14.29 \%$ cases.
A variety of post-operative complications occurred in a number of patients. These were pneumonia, paralytic ileus, wound infection, wound dehiscence and fistula. The commonest complication was varying degrees of wound sepsis in $51 \%$ patients followed by paralytic ileus in $38 \%$ patients. Duodenal fistula occurred in $5 \%$ patients. More than one complication occurred in same patient.

Median hospital stay was $(\bar{X} \pm$ SD) $10 \pm 6.03$ days. Out of 100 cases $55 \%$ patients stayed in hospital upto 9 days, $25 \%$ patients stayed upto $10-18$ days, $15 \%$ patients upto $20-30$ days and $5 \%$ patients stayed $>30$ days.

The overall mortality in 100 cases was $5 \%$. Out of 5, 3 cases died due to septicaemia and multiple organ failure following duodenal fistula. Two patients died in post-operative period due to shock.

Data analyzed by appropriate statistical method (Mean, SD \& $\lambda^{2}$ test).

\section{RESULTS}

The relationship between age of patients \& outcome of treatment in terms of mortality was found to be highly significant $(\mathrm{p}<0.001) \quad($ Table-I). The association between increased age and postoperative complications was found to be significant $(\mathrm{p}<0.05)$ (Table-II).

Table 1: Age of the patients and outcome of treatment.

\begin{tabular}{|c|c|c|c|c|}
\hline \multirow[t]{2}{*}{ Age } & \multicolumn{2}{|c|}{ Outcome of treatment } & \multirow[t]{2}{*}{ Total } & \multirow[t]{2}{*}{ p-value } \\
\hline & Cure & Death & & \\
\hline Upto 50 years & $\begin{array}{r}86 \\
(81.7)\end{array}$ & $\begin{array}{r}0 \\
(4.3)\end{array}$ & 86 & $\mathrm{p}<0.001$ \\
\hline Above 50 years & $\begin{array}{r}9 \\
(13.3)\end{array}$ & $\begin{array}{r}5 \\
(0.7)\end{array}$ & 14 & \\
\hline Total & 95 & 5 & 100 & \\
\hline
\end{tabular}

Table 2: Age of the patients \& postoperative complications.

\begin{tabular}{lrrrr} 
Age & \multicolumn{2}{c}{$\begin{array}{c}\text { Complications } \\
\text { Developed }\end{array}$} & Total & Not \\
developed & & \\
Upto 50 years & 44 & 42 & 86 & \\
& $(47.3)$ & $(38.7)$ & & $\mathrm{p}<0.05$ \\
Above 50 years & 11 & 3 & 14 & \\
& $(7.7)$ & $(6.3)$ & & \\
Total & 55 & 45 & 100 &
\end{tabular}

All the 5 deaths were observed in the patients which were operated after $24 \mathrm{hrs}$ of onset of symptom. On the other hand no death was observed in patients operated within $24 \mathrm{hrs}$ of onset of symptom. Significant relationship $(p<0.05)$ was found between delayed operation and outcome of treatment in terms of mortality (Table III). 
Table 3: Delayed operation and outcome of treatment.

\begin{tabular}{lrrrr}
$\begin{array}{l}\text { Time interval } \\
\text { between onset } \\
\text { symptom and } \\
\text { operation }\end{array}$ & Cutcome of treatment & Death & Total & p-value \\
After 24 hours & 43 & 5 & 48 & \\
& $(45.6)$ & $(2.4)$ & & $\mathrm{p}<0.05$ \\
Within 24 hours & 52 & 0 & 52 & \\
& $(49.4)$ & $(2.6)$ & & \\
Total & 95 & 5 & 100 & \\
\hline
\end{tabular}

Various post operative complications were developed in patients which were operated after $24 \mathrm{hrs}$ onset of symptoms. Complications were observed in patients which were operated within 24 hrs of onset of symptom. So, the association between delayed operation $\&$ post operative complications was found to be highly significant $(\mathrm{p}<0.001)$ (Table IV).

Table 4: Delayed operation \& post-operative complications.

\begin{tabular}{lrrrr}
$\begin{array}{l}\text { Time interval } \\
\text { between onset } \\
\text { symptom and } \\
\text { operation }\end{array}$ & $\begin{array}{r}\text { Complications } \\
\text { Developed }\end{array}$ & $\begin{array}{c}\text { Not } \\
\text { developed }\end{array}$ & & Total \\
After 24 hours & 45 & 3 & 48 & \\
Within 24 hours & $126.4)$ & $(21.6)$ & & $\mathrm{p}<0.001$ \\
& $(28.6)$ & 42 & 52 & \\
Total & 55 & 45 & 100 & \\
\hline
\end{tabular}

There was longer hospital stay in patients operated after 24 hours. Significant relationship $(\mathrm{p}<0.001)$ was found between delayed operation and median hospital stay (Table V).

Table 5: Delayed operation \& median hospital stay.

\begin{tabular}{lrrrr}
$\begin{array}{l}\text { Time interval } \\
\text { between onset } \\
\text { symptom and } \\
\text { operation }\end{array}$ & $\begin{array}{l}\text { Grouping of patients by } \\
\text { median hospital stay } \\
\text { Above } \\
\text { median }\end{array}$ & $\begin{array}{c}\text { Upto } \\
\text { median }\end{array}$ & Total & p-value \\
After 24 hours & 43 & 5 & 48 & \\
& $(22.08)$ & $(25.92)$ & & p $<0.001$ \\
Within 24 hours & 3 & 49 & 52 & \\
& $(23.92)$ & $(28.08)$ & & \\
Total & 46 & 54 & 100 & \\
\hline
\end{tabular}

Mortality rate was higher in patients with purulent peritoneal fluid. It was nil in serosanguinous and billous type. The association between nature of peritoneal fluid and outcome of treatment was highly significant $(\mathrm{p}<0.001)$ in terms of mortality (Table-VI). There was more different postoperative complication in patients having purulent peritoneal fluid in comparison to billous \& serosanguinous nature. The association was found to be highly significant $(\mathrm{p}<0.001)$ (Table VII).
Table 6: Nature of peritoneal fluid and outcome of treatment.

\begin{tabular}{lrrrr}
$\begin{array}{l}\text { Nature of } \\
\text { peritoneal fluid }\end{array}$ & \multicolumn{2}{l}{$\begin{array}{l}\text { Outcome of treatment } \\
\text { Cure }\end{array}$} & $\begin{array}{c}\text { Total } \\
\text { Death }\end{array}$ & p-value \\
Billous & 53 & 0 & 53 & \\
& $(50.35)$ & $(2.65)$ & & $\mathrm{p}<0.001$ \\
Purulent & 31 & 5 & 36 & \\
& $(34.20)$ & $(1.80)$ & & \\
Serosanguinous & 11 & 0 & 11 & \\
& $(10.45)$ & $(0.55)$ & & \\
Total & 95 & 5 & 100 & \\
\hline
\end{tabular}

Table 7: Nature of peritoneal fluid and postoperative complication.

\begin{tabular}{lcccc}
$\begin{array}{l}\text { Nature of } \\
\text { peritoneal fluid }\end{array}$ & $\begin{array}{c}\text { Complication } \\
\text { Developed }\end{array}$ & $\begin{array}{c}\text { Not } \\
\text { developed }\end{array}$ & Total & p-value \\
Billous & $\begin{array}{r}17 \\
(29.15)\end{array}$ & $\begin{array}{r}(23.85) \\
\text { (15) }\end{array}$ & 53 & \\
Purulent & 35 & 1 & 36 & \\
& $(19.8)$ & $(16.2)$ & & \\
Serosanguinous & 3 & 8 & 11 & \\
& $(6.05)$ & $(4.95)$ & & \\
Total & 55 & 45 & 100 & \\
\hline
\end{tabular}

Mortality rate was higher $(\mathrm{p}<0.001)$ in patients with preoperative shock than patients presented with no features of preoperative shock (Table-VIII).

Table 8: Preoperative shock and outcome of treatment.

\begin{tabular}{lrrrr}
$\begin{array}{l}\text { Features } \\
\text { preoperative } \\
\text { shock }\end{array}$ & Outcome of treatment & Total & $\mathrm{p}$-value \\
& Cure & Death & & \\
Present & 8 & 4 & & \\
& $(11.4)$ & $(0.6)$ & 12 & $\mathrm{p}<0.001$ \\
Absent & 87 & 1 & 88 & \\
& $(83.6)$ & $(4.4)$ & & \\
Total & 95 & 5 & 100 & \\
\hline
\end{tabular}

Higher complication rate was observed in patients having feature of preoperative shock. The relationship was found to be significant $(\mathrm{p}<0.01)$ (Table IX).

Table 9: Preoperative shock and postoperative complications.

\begin{tabular}{|c|c|c|c|c|}
\hline \multirow{2}{*}{$\begin{array}{l}\text { Features } \\
\text { preoperative } \\
\text { shock }\end{array}$} & \multicolumn{2}{|c|}{ Complication } & \multirow[b]{2}{*}{ Total } & \multirow[b]{2}{*}{ p-value } \\
\hline & Developed & Not developed & & \\
\hline Present & $\begin{array}{r}11 \\
(6.6)\end{array}$ & $\begin{array}{r}1 \\
(5.4)\end{array}$ & 12 & $\mathrm{p}<0.01$ \\
\hline Absent & $\begin{array}{r}44 \\
(48.4)\end{array}$ & $\begin{array}{r}44 \\
(39.6)\end{array}$ & 88 & \\
\hline Total & 55 & 45 & 100 & \\
\hline
\end{tabular}




\section{DISCUSSION}

The present series comprises study of 100 cases of chronic duodenal ulcer perforation patients undergone operative management in the form of simple repair with interposition of omental patch and thorough peritoneal toileting. Highest number of incidence occurred in fourth decade of life with male preponderance, the ratio being 9:1. All patients presented with typical acute upper abdominal pain, $12 \%$ in a state of actual shock. In $71 \%$ cases there were positive history suggestive of chronic peptic ulcer. $14 \%$ cases were of above 50 years of age.

Increased interval between onset of symptom and operation is closely related to postoperative mortality and morbidity in the large present series. It is clearly evident from other publication $^{12,13,14,15}$ as well as from present series that there are more deaths among patients with longstanding perforation. It is highly statistically significant in all analyses that, delayed treatment after perforation causes reduced survival, increased complications and prolonged hospital stay.

The gradual increase in risk with increasing delays and the magnitude of the observed effects supports the notion of delay as a critical prognostic factor for outcome. Observed mortality and morbidity are higher than any other series indicates effects of delayed treatment following late presentation in the present series. However, only one factor (delay) is unlikely to be responsible for the mortality. Associated comorbid factors as shock on admission also markedly influence the outcome. The critical for delayed presentation having negative effects seems to be approximately 24 hours. As recent studies showed that duodenal perforations are sterile for the first 12 hours and then become contaminated. This may explain why frequency of adverse effects increases with increasing delay. Treatment delay is a determining factor for survival after ulcer perforation.
Elderly patients are another vulnerable group suffering from chronic duodenal ulcer perforation with vague and atypical presentation. The frequency of complication increases markedly in age group more than 50 years which is reflected in the series. Lethality in patients less than 50 years was low. Morbidity in this series is higher among elderly.

Antibiotics are not an alternative of surgical intervention. Resuscitation is definitively a very important measure in all cases of perforation management. It appears from the study that preoperative shock is an important prognostic factor in relation to postoperative mortality and morbidity. It is often difficult to overcome preoperative shock adequately with limited facilities. It leads patients with subsequent surgical intervention more risky. Also postoperative complications are prevalent among them.

Gross peritoneal sepsis poses a great therapeutic problem and accounts for most of the deaths in perforation patient. There are more complications in the form of wound infection, wound dehiscence and fistula in that group even with optimum supportive efforts. All these ultimately prolong hospital stay of the patients with various long term complications.

\section{CONCLUSION}

Delayed operation, preoperative shock, more age and gross peritoneal sepsis bear a direct relationship with outcome of treatment chronic duodenal ulcer perforation patients. Early detection, referral, adequate preoperative resuscitation and timely surgical intervention have therefore a direct therapeutic implication in the management of chronic duodenal ulcer perforation patients.

\section{DISCLOSURE}

All the authors declared no competing interest.

\section{REFERENCES}

1. Niwaya G, Terplan K. A study of peptic ulcer based on necropsy record. Gastroenterology 1959; 36: 409-422.

2. Hasan M, Ali SMK, Azad KAK. Peptic ulcer in Bangladesh- an endoscopy survey. Gut 1985; 16: A 1117.

3. Tobey FI. Peptic ulcer in India and Bangladesh. Gut 1979; 20: 329.

4. Friedman G. Peptic ulcer disease. Clinical Symposia. Ciba-Geigy 1988; 40:1.

5. Colley S. Peptic ulcer disease. Practitioner 1991; 253: 233-238.

6. Alam MM. Incidence of duodenal ulcer and its surgical management in a teaching hospital in Bangladesh. Tropical doctor 1995; 25:67-68.

7. Aird. I. Perforated peptic ulcer, companion in surgical study: $2^{\text {nd }}$ edn. 1958.

8. Maingot R. Abdominal operation vol.-I, $9^{\text {th }}$ edn, 1990; 629-632.

9. Lawrence W. Way. Perforated peptic ulcer. Current Surgical Diagnosis and Treatment, $10^{\text {th }}$ edn. 1994; 492-494.

10. R.C.G. Russel, Norn S. Williams \& Christopher J.K. Bulstrode. Perforated peptic ulcer. Bailey \& Love's Short Practice of Surgery, $23^{\text {rd }}$ edn. 2000; 911-912.

11. Azad, Khondker Abul Kalam. Risk stratification in perforated duodenal ulcer: a prospective evaluation of predictive factors, 1992, BCPS dissertation. Accession no 1101-2.

12. Kozoll DD, Meyer KA. General factors influencing the incidence and mortality of acute perforated gastroduodenal ulcers. Surg. Gynec. Obst. $1960 ; 111: 607$.

13. Braun L. Surgical therapy of ulcer disease. Early and late results of elective and emergency interventions. Chirurg. 1991; 62(9): 681-685.

14. Svanes C et al. Perforated peptic ulcer. An analysis in the increase in treatment delay 1935-85. Surg. Res. Comm. 1989; $6: 181-188$.

15. Noordijk JA. Perforated peptic ulcer: the results of treatment in the Netherlands (1934-50). An analysis of 2551 cases. Arch. Chir. Neerl. 1953; 5: 262-270. 